\title{
Alasdair MacIntyre, Ethics in the Conflicts of Modernity. An Essay on Desire, Practical Reasoning and Narrative
}

\author{
Gustavo Arosemena
}

Alasdair MacIntyre, Ethics in the Conflicts of Modernity. An Essay on Desire, Practical Reasoning and Narrative (Cambridge: Cambridge University Press, 2016), 332 p.

In this book Alasdair MacIntyre confronts two rival accounts of practical reasoning. One based on the satisfaction of individual desires and another based on the achievement of human flourishing. MacIntyre sets out to vindicate the latter as superior. The theory of practical reasoning which gives emphasis to the satisfaction of desires descends from the work of David Hume and takes modern form in the meta-ethical doctrine of expressivism. According to expressivism ethical judgements are subjective expressions of emotion, attitude or commitment; not the sorts of things that can be true or false. For an expressivist, to say that murder is wrong is ultimately to say that he disapproves or feels outrage at murder. The theory of flourishing that MacIntyre defends in opposition to expressivism is a form of Aristotelian teleology. According to teleology the good is what objectively fulfills our natures as rational animals. For a teleologically oriented thinker, to say that murder is wrong is not to express an emotion, but rather to state that murder is detrimental to human flourishing. MacIntyre claims that the choice between expressivism and teleology is the most fundamental moral polemic of modern times.

While expressivism is a meta-ethical doctrine, that is, a doctrine about the metaphysical nature of ethical judgments, and not a social or political doctrine, MacIntyre's main claim is not to show that expressivism is inadequate as a theory, but rather to show that it is the outgrowth and the mask of a defective ethical culture. It is not only that expressivism is mistaken, but rather that it serves 'to conceal and disguise' the true conditions of our social and economic order. This line of argument against expressivism is not wholly new. It is prefigured in MacIntyre's critique of existentialism in Notes From the Moral Wilderness (1958), it appears also in After Virtue (1981) and elsewhere in his work, but this book takes this critique to a higher level, elevating it from a fertile suspicion to a detailed indictment of modern ethical thinking.

This book represents a return to Marx for MacIntyre. While MacIntyre begun his academic career as a Marxist, Marx is largely absent from his mature works: After Virtue, Whose Justice, Which Rationality (1988), Three Rival Versions of Moral 
Inquiry (1990), and Dependent Rational Animals (1999). By contrast, Marx plays a significant role in this book. He is presented alongside Aristotle and Aquinas as a thinker who can help us go beyond the obfuscations of expressivism. This return to Marx is fitting. The claims that MacIntyre develops in this book ultimately harken back to his time as a socialist coming to terms with Stalinism (see the aforementioned Notes From the Moral Wilderness), and the argumentative strategy deployed against expressivism is distinctly Marxian in character. Expressivism is refuted by unmasking it as a cover for pernicious social tendencies.

As the argument develops, MacIntyre shows that expressivism exhibits a problematic tendency to accept the most basic responses of individual human beings as unquestionable givens and to frame social problems as problems of administration of existing wants, leaving no room for radical critique. This can already be seen in the work of Hume, who assumed that the moral sentiments of the England of his time, prizing industriousness, avarice and wealth, were natural sentiments and not local beliefs, while ignoring the plight of the poor who lived in conditions of 'judicial terror.' It can also be seen in capitalism, which tries to satisfy an infinite range of unquestioned and unquestionable desires while at the same time ignoring or undermining real human goods and needs. Modern economic thinking provides little to no guidance as to how to distinguish mere wants from real needs. And it can be seen in the work of authors such as D.H. Lawrence and Bernard Williams who find that morality is worthless if it is not responsive to their most basic impulses. Neither Lawrence nor Williams have the resources to question their basic desires should they be destructive or vile.

MacIntyre's alternative to expressivism is teleology. Teleology is easily deployed in the natural world. It is good for oak trees to flourish in ways that are appropriate for oak trees. It is good for wolves to flourish in ways that are appropriate to wolves, irrespective of what we feel about this. Human beings can intelligibly question whether living in accordance to nature is good or bad but this does not render teleology useless. It is part of our nature to seek the good through reason, but this must take place within the framework of our existence as socially situated rational and dependent animals. Our nature constrains the outer bounds of the process of reflection. Dialectic and narrative inquiries complement and build upon natural teleology as practical reasoning moves in concentric circles from our nature as a species, to our social situation, to our individual life: Human beings must examine their social and historical worldviews in order to determine what is most conductive to human flourishing. This can only be done by questioning the totality of one's own theoretical and practical commitments in light of rival theories of the good. And human beings must seek to find ways to recognize their lives as a meaningful whole. This involves retelling one's own personal history in more adequate and truthful ways.

Teleology so described has a depth that expressivism lacks. For teleological thinkers individual desires are not unnegotiable. Rather they are accountable to, and must be made to fit with, the overarching demands of human flourishing. And our individual desires have to be recognized as the product of a social order that 
must be subject to rational scrutiny as well. The fruits of such expanded horizons can be seen in the social and individual forms of life that teleological thinking enables and encourages. MacIntyre presents us examples of communities in Denmark (the Thorupstrand fishing community) and Brazil (the Monte Azul favela) that have succeeded in creating modes of social organization that put human needs in the forefront. At the individual level, he presents figures such as Vassily Grossman and C.L.R. James as examples of human beings who could successfully understand their life stories as a meaningful and truthful narrative in spite of personal failures and in spite of being embedded in a highly dysfunctional social environment. These communities and individuals exhibit a great responsiveness to the demands of human flourishing that is dependent on their ability to go beyond superficial wants and commitments.

While I see MacIntyre's critique as being on the whole successful, I disagree with MacIntyre's diagnosis that the core problem of ethics today lies with the limitations of expressivism. It seems to me that the core problem of ethics today is making sense of the idea that there are certain things, such as torture and the murder of the innocent, that should never be done and it is not clear that MacIntyre's teleology puts us in a better position to address this problem. MacIntyre in fact wavers from accepting absolute prohibitions, to recommending an uncommitted 'case-by-case' approach to moral dilemmas that is suggestive of difficulties in coming to terms with this problem. MacIntyre wants us to look at human flourishing and not individual desires, but it seems that some degree of flourishing can be pursued, and possibly achieved, through vile means. The problem of 'absolute prohibitions' is all the more urgent given MacIntyre's persistent rejection of human rights.

The book is easy to read and not steeped in technicality. In comparison with the mainstream of moral philosophy, this book must be prized for the wealth of historical, sociological and biographical information that accompanies its argument. It is one thing to imagine a possible problem, another to present it as actual. The main readership of the book will naturally be moral and political philosophers, but it should be significantly interesting for legal philosophers and theoretically minded lawyers. Inevitably, legal professionals form part of the expressivist culture that MacIntyre critiques, and unacknowledged expressivism quite often narrows and impoverishes their thinking. If MacIntyre is right, expressivism is an obstacle for lawyers to understand their place in our often barbaric civilization. Such understanding is needed if lawyers are to truly flourish.

In integrating natural teleology, dialectic and narrative, Aristotle, Aquinas and Marx, this book seems to bring together many of MacIntyre's intellectual endeavors into a single vision whose comprehensiveness is understated by the anti-climactic tone of the book. After Virtue ends by forcing the reader to choose between Nietzsche and Aristotle, and to embrace both Trotsky and St. Benedict as a dark age draws near. By contrast, this book ends with a series of biographical vignettes. The modest tone of the book does not detract from its significance. 